\title{
Histo-Morphological Study on the Footpad of Os- trich (Struthio camelus) In Relation to Locomotion
}

\author{
S.A.A. El-Gendy ${ }^{a}$, Amira Derbalah $^{b}$, M.E.R. Abu El-Magd ${ }^{c}$ \\ ${ }^{a}$ Department of Anatomy and Embryology, ${ }^{b}$ Histology, Faculty of Veterinary Medicine, \\ Alexandria University, Edfina, Behera, Egypt and ${ }^{\mathrm{C}}$ Department of Anatomy and Embry- \\ ology, Faculty Veterinary Medicine, Kafr el sheikh University, Egypt
}

\section{Abstract}

The ostrich foot has four digital pads, two on the $3^{\text {rd }}$ digit, one on the $4^{\text {th }}$ digit and one at metatarsophalangeal joint. Although these footpads are essential for long distance locomotion of the ostrich, no published data is available on the structure of these footpads. Therefore, the aim of this study is to examine the histo-morphological structure of these footpads in an attempt to highlight their structural functional adaptation for long distance motion. Morphologically, the ventral surface of each footpad is covered by numerous papillae which are varied in direction, length and thickness. In histological examination, the epidermis of the footpad consists of outer stratum corneum and inner stratum germinativum (which is subdivided into basal, intermediate and transitional layers). The stratum corneum has several layers of flat- tened horney cells. The nuclei of the basal cells have several mitotic figures. The cytoplasm of the stratum germinativum cells has multiple lipid droplets and multigranular bodies (in transitional cells only). Using scanning electron microscope, the collagen fibers in the mid and deep dermis of the footpad run parallel and connect to each other by very thin fibrils which are branched, crossed with each other in an oblique direction. Such arrangement of these collagen fibers and thin fibrils and presence of digital cushion are likely to be responsible for absorption of concussion and hence acceleration of the ostrich movement. We have concluded that ostrich footpads have unique modified structures which are adapted for long distance movement and protection of the underlying soft tissues. 


\section{Key wards}

foot pads, digital cushion, morphology, electron microscopy, ostrich

\section{Introduction}

Egyptian ostrich (Struthio camelus) was widely distributed in the past. However, as a result of climatic changes and intensive hunting by humans, ostrich number gradually declined until disappearing from Egypt by 1990s (Manilus, 2002). At the beginning of $21^{\text {th }}$ century it reappears again and grows in farms. Recent interest in ostrich farming has led to an increasing demand for information about this bird and how to manage it in a commercial environment. Ostrich farming is very important for production of feather, meat, skin and eggs (Cooper et al., 2008). Leather is one of the main products derived from ostrich farming (Meyer et al., 2002).

In general, the foot skin consists of an outer epidermis and an underlying, thicker dermis. The epidermis and dermis give rise to many structures, e.g. footpads, feathers, claws, nails, scales and beak. The footpad is a soft fleshy area on the planter surface of a bird foot, where the three large digits meet (Bennett, 1997). The epidermis of the foot pad of fowl consists of basal layer, gra- nular (transitional) layer and horny layer (Shtekher, 1966). The dermal connective tissue grew into epithelium in the form of papillae. Dermal papillae, which are usually absent in the bird skin except in the foot and beak, are also found throughout the skin in the ostrich (Deeming, 1999). The prickle cell layer of the foot pad of the fowl is thicker than in other sites and graded into deep transitional region. Unlike in fowl, the foot pad of ostrich has a digital cushion. Digital cushion represents a thick layer of connective tissue in the depth of the digital pad. Cushions serve to absorb mechanical shock and to support the limb (König et al., 2003).

Although the footpads and digital cushions are very pronounced in terrestrial birds, and play an essential role during locomotion (Shanawany and Dingle, 1999), no data is available on the histomorphology of these structures. As terrestrial bird, ostriches (Struthio camelus) are an interesting bird in which to examine foot skin structure and properties. Firstly, they are able to walk or run for very long distance. Secondly, they have only two toes on each foot with large footpads and digital cushions make it a simple task to cut regular specimens and thirdly, they are farmed for meat so material is readily available. 
Ostriches are considered as excellent long-endurance runners, capable of running with a speed of 60 $\mathrm{km} / \mathrm{h}$ for duration exceeding twenty minutes while reaching peak velocities up to $80 \mathrm{~km} / \mathrm{h}$ - surpassing the locomotor abilities of their ratite relatives (Alexander et al., 1979 and Hallam, 1992). Therefore, the majority of studies were focused on studying the morphology of the musculo-skeletal system of ostrich (Keast, 1996 and Raikow, 1985). However, a little is known about the structure of ostrich skin. Therefore, the aim of study is to describe the macroscopic and microscopic anatomical structures of footpad and digital cushion of ostrich. This will give insight into the structural functional relationship of the ostrich footpad and explain how ostrich foot adapted for long distance walk/run in desert land.

\section{Materials and Methods}

\section{Samples}

Ten feet of healthy 1.5 - 2 years ostrich, brought from local slaughter house inside Emad farm at $68 \mathrm{~km}$ at Alex- Cairo desert road were sagittally sectioned and various diameters of footpads, their papillae and digital cushions were measured.

\section{For light microscope}

Small pieces from different parts the skin of both footpad and digital cushions were fixed in $10 \%$ neutral buffered formalin for $48 \mathrm{hrs}$ then dehydrated in ascending grades of ethyl alcohol. They were cleared in xylene and embedded in three changes of paraffin. The paraffin blocks were cut at $6 \mu \mathrm{m}$ thick and stained by:

1. Harris hematoxylin and eosin stain (H\&E) for general studies (Harris, 1900).

2. Masson trichrome stain for the detection of muscular tissue, blood vessel, and collagen fiber (Masson, 1929).

\section{For scanning electron micro- scopy}

Small specimens from the foot pads skin were immediately immersed in a fixative (2\% formaldehyde, $1.25 \%$ glutaraldehyde in $0.1 \mathrm{M}$ sodium cacodylate buffer, $\mathrm{pH} 7.2$ ) at $4^{\circ} \mathrm{C}$. Once fixed, the samples were washed in $0.1 \mathrm{M}$ sodium cacodylate containing $5 \%$ sucrose, processed through tannic acid, and finally dehydrated in increasing concentrations of ethanol (15 min each in 50, $70,80,90,95$ and $100 \%$ ethanol). The samples were then critical-point dried in carbon dioxide, attached to stubs with colloidal carbon and coated with gold- palladium in a sputtering device. Specimens were examined and photographed with a 
Jeol scanning electron microscope operating at $15 \mathrm{Kv}$.

\section{For transmission electron mcros- copy}

Small cubes $\left(1 \mathrm{~mm}^{3}\right)$ of footpad skin were immediately fixed in a $6 \%$ solution of phosphate-buffered glutaraldehyde, $\mathrm{pH} 7.4$, at $4^{\circ} \mathrm{C}$ for $6 \mathrm{~h}$ (McDowell and Trump, 1976). After initial fixation, tissues were washed in several changes of cold $\left(4^{\circ} \mathrm{C}\right) 0.1$ $M$ phosphate buffer every 15 min for $2 \mathrm{~h}$. Samples were then rapidly dehydrated through increasing concentrations of ethanol, transferred to propylene oxide and placed overnight in a 1:1 mixture of propylene oxide and epoxy araldite. Semi-thin sections $(1 \mathrm{~mm})$ were first cut and stained with toluidine blue and viewed with light microscopy to specify areas suitable for transmission electron microscopy. Ultrathin sections $(60-100 \mathrm{~nm})$ were then cut by a glass knife with an L.K.B. microtome and stained with uranyl acetate followed by lead citrate (Hayat, 1986). The ultrathin sections were examined with a Jeol transmission electron microscope operating at $100 \mathrm{Kv}$

\section{Results}

\section{1- Morphological examination A- Footpads}

The ostrich foot is didactyl, 22-28 $\mathrm{cm}$ long and $10-12 \mathrm{~cm}$ wide, consisting of digits III and IV (fig.1). The two digits are partially connected by interdigital septum (Fig.4/7). Each foot has four digital pads; metatarsal phalangeal pad, two pads on digit III and one pad on digit IV (Fig.1). The metatarsal phalangeal pad is rounded, measured $3.5 \mathrm{~cm}$ in diameter and is present at the joint between the basal phalanges and the tarso-metatarsus (Fig.1/1). It carries dome-shaped and closely adherent papillae (55-60 papillae $/ \mathrm{cm}^{2}, 0.3 \mathrm{~cm}$ high, Fig. $1 / 1^{-}$). The integument of sole of digit IV has only one ovoid footpad (9-10 $\mathrm{cm}$ long, 2-3 cm wide and 0.4-0.5 $\mathrm{cm}$ thick, Fig.1/2). It extends underneath the digital cushion from the level of the distal third of the $1^{\text {st }}$ phalanx to the end of the $5^{\text {th }}$ phalanx (Fig.3/8). It carries papillae which have nearly the same size (0.4-0.6 $\mathrm{cm}$ long and 0.1 wide, Fig.1/2'). These papillae are directed cranially at the cranial third, vertically in the middle third and caudally in the caudal third of the footpad.

The integument of sole of digit III has two digital pads, caudal (Fig.1/3) and cranial (Fig.1/4), which are separated by interpad groove ( 7 $\mathrm{cm}$ long, $0.6 \mathrm{~cm}$ wide and $0.4 \mathrm{~cm}$ thick) (Fig.1/5). The caudal footpad is short oval, $7 \mathrm{~cm}$ long, $6.5 \mathrm{~cm}$ wide, 
$1.4 \mathrm{~cm}$ thick and extends underneath the digital cushion from the level of the middle part of the $1^{\text {st }}$ phalanx to the middle part of the $2^{\text {nd }}$ phalanx (Fig. 1/3 and 2/7 ). The papillae in the center of this pad have blunt ends (45 - 48 papillae $/ \mathrm{cm}^{2}, 0.7-0.8 \mathrm{~cm}$ long and $0.2 \mathrm{~cm}$ thick, Fig. 1/ $3^{-}$), while the papillae in the periphery have $\left(60\right.$ papillae $/ \mathrm{cm}^{2}$, $1.2 \mathrm{~cm}$ long, $0.1-0.15 \mathrm{~cm}$ thick, Fig.1/ 3). All these papillae have polygonal origin (Fig.1/3). On the other hand, the cranial pad is elongated oval in shape, $9-10 \mathrm{~cm}$ long, $7-8 \mathrm{~cm}$ wide, $1.1 \mathrm{~cm}$ thick and extends from the middle portion of the $2^{\text {nd }}$ phalanx to the middle portion of the $4^{\text {th }}$ phalanx (Fig.2/9). The central part of this pad carries blunt papillae with vertically directed ends (47-50 papillae $/ \mathrm{cm}^{2}, 0.5-0.6 \mathrm{~cm}$ long and $0.2 \mathrm{~cm}$ thick, Fig.1/4\&4). Whereas, the periphery of this pad has pointed papillae with curved ends (55-57 papillae $/ \mathrm{cm}^{2}, \quad 0.7-0.8 \mathrm{~cm}$ long and $0.15 \mathrm{~cm}$ thick, Fig.1/4\&4).

\section{B- Digital cushions}

The digit III has two digital cushions, a large abaxial one (Fig. 4/1) and a smaller axial one (Fig. 4/2). The abaxial cushion extends from the level of the distal extremity of the $1^{\text {st }}$ phalanx to the proximal extremity of the $4^{\text {th }}$ phalanx $(13 \mathrm{~cm}$ long, $2.5 \mathrm{~cm}$ wide and $1.4 \mathrm{~cm}$ thick at level of the $1^{\text {st }}$ interphalangeal joint, $0.8 \mathrm{~cm}$ thick at the $2^{\text {nd }}$ interphalangeal joint, 0.3 $\mathrm{cm}$ thick at the $3^{\text {rd }}$ interphalangeal joint, fig. $4 / 1$ and 2/10). The axial cushion is $13 \mathrm{~cm}$ long, $2 \mathrm{~cm}$ wide and has the same thickness of the abaxial one (fig. 4 / 2). The two cushions are separated by $0.3 \mathrm{~cm}$ wide groove which is filled by fibrous connective tissue (fig. $4 / 3$ ). The cushions are enclosed within a fibrous capsule (fig. 4/5) and fixed dorsally by fibro-elastic tissue with the related tendons.

The fourth digit has only one cushion which extends from the level of the distal extremity of the $1^{\text {st }}$ phalanx to the distal extremity of the $5^{\text {th }}$ phalanx $(8 \mathrm{~cm}$ long, $1 \mathrm{~cm}$ wide and $0.9 \mathrm{~cm}$ thick at level of the $1^{\text {st }}$ interphalangeal joint, $0.7 \mathrm{~cm}$ thick at the $2^{\text {nd }}$ interphalangeal joint and $0.3 \mathrm{~cm}$ at the $3^{\text {rd }}$ and $4^{\text {th }}$ interphalangeal joints (Fig. 3/7 and 4/4).

\section{2- Microscopic examination}

\section{A- Footpads}

Histological examination of the skin of the digital pad of ostrich revealed the presence of highly cornified papillae which consist of core of stratified squamous keratinized epithelium (epidermis) and C.T (dermis) completely surrounded by several layers of keratin (Fig.5\&6). The epidermis of digital pad is composed of stratified squamous keratinized epithelium which has 2 layers; inner 
stratum germinativum and outer stratum corneum (Fig. 6).

\section{1- Epidermis}

\section{a- Stratum Germinativum}

The stratum germinativum is subdivided into 3 layers; basal, intermediate and transitional layers. The basal layer consists of tall columnar epithelial cells with large oval nuclei. Some nuclei showed mitotic figures (Fig. 7), and small darkly stained cytoplasm, containing some lipid droplets (Fig. 9). The plasma membrane of each cell is folded and interdigitated with that of the adjacent cells. Desmosomes are seen among neighboring basal cells. The basal lamina evaginates into the underlying dermis (Fig. 9) and studded with some hemidesmosomes (Fig. 10).

The intermediate layer consists of one to several layers of polygonal cells (Fig. 7) with peripherally located nuclei and darkly stained cytoplasm containing multiple lipid droplets which fuse with each other forming large droplets (spaces) on the expense of the organelles which become very scanty (Fig. 12). Interdigitations of plasma membrane of adjacent cells are also apparent in this layer.

The transitional layer is thin and consists of flattened cells; their cytoplasm was vacuolated (Fig.8). Transmission electron microscope
(TEM) pictures revealed that the cytoplasm of these cells is filled with fibrous amorphous materials (tonofibrils) with few keratohyaline masses dispersed among them (Fig. 11). In addition, multiple lipid droplets and multigranular bodies containing electron lucent material are found toward the cells of stratum corneum (Fig. 11).

\section{b- Stratum Corneum}

The stratum corneum is thick and consists of several layers of keratin. Some keratin layers are loosely arranged with several spaces between them, while the others are tightly packed with few empty spaces (Figs.7\&8). There is a sharp demarcation between transitional layer and keratinized layer (Figs. 7\&8). TEM pictures revealed that this layer consists of several layers of strongly flattened horney cells devoid of intracellular material with an outer conrnified layer assumed to be keratin (Figs. 13\&14). Some cells continue to reveal remnants of lipid droplets surrounded by a fibrousamorphous mass, while the others contain lamellae (Figs. 13\& 14). Some interdigitations are found between the cells.

Scanning electron microscope examination of the epidermis of footpad revealed the presence of slightly overlapped hexagonal 
squamous cells arranged in layers (Fig.15).

\section{2-Dermis}

The dermis consists of two layers; superficial and deep. Light microscopic (LM) examination of sections of the superficial dermal layer stained with Trichrome revealed that this layer is thin and consists of loosely arranged C.T characterized by the presence of multiple dermal papillae (Fig. $16 \& 17$ ). In addition, TEM examination revealed that this layer consists of loosely arranged collagen fibrils and fibroblast (Fig.10).

The deep dermal layer is thick and consists of dense irregular C.T with numerous smooth muscle fibers and blood vessels (Figs. 6 \& 17). TEM revealed the presence of closely packed and discretely organized collagen fibrils (Fig. 18) in this layer. Longitudinal section of collagen fibrils displays the normal periodic banding, while cross section of collagen fibrils displays broad range in fibrils diameters which have a hexagonal appearance (Figs. $19 \& 20$ ). Stellate (inactive) fibroblast; with short cytoplasmic processes, darkly stained nuclei and few ribosomes in the cytoplasm; have been found between collagen fibrils (Fig. 21).

Scanning electron microscope examination of the upper layers of

dermis showed that the collagen fibers run parallel to each other and diagonally to the skin surface (Fig.22). On the contrary, all of the collagen fibers in the mid and deep dermis are arranged parallel to each other (Fig.23). Some of these collagen fibers are tightly packed, whereas some others are separated by small spaces. These spaces contain extremely thin branched fibrils (trabeculae) which connect between parallel collagen fibers and cross each other in an oblique direction (Figs.23\&24).

\section{B- Digital cushions}

Histological examination of $\mathrm{H} \& \mathrm{E}$ and toludine blue stained sections of the digital cushion revealed the presence of numerous adipocytes, few fibroblasts, scarcely collagen fibers and blood vessels (fig. 25\&26).

\section{Discussion}

The distal foot areas of terrestrial creatures that contact with ground are characterized by the presence of highly modified skin along with digital cushions and/ or footpads which are designated to withstand compression. Its damage leads to bacterial infection and bumble foot. Although, many studies have determined the structure and the me- 
chanical properties of this modified skin in mammal, nothing is known about the histomorphological structure of footpads and digital cushions in terrestrial birds, such as ratites (ostrich, emu, cassowary, rhea, kiwi), which are a group of terrestrial birds that has become most highly adapted to terrestrial locomotion as they are all flightless birds. In this study, we have examined the histomorphological structure of the footpads and digital cushions on the ostrich two digits (digit III and IV). We have found that the ostrich foot has four footpads, two on digit III, one on digit IV and one at metatarso-phalangeal joint. Because digit III has four phalanges and digit IV has 5 phalanges, the footpads do not reflect the number of phalanges in these digits. In contrast to ostrich, the digital pads in the digits II and III of emu clearly reflect the number of phalanges in the digits. In agreement with Shanawany and Dingle (1999), the plantar surface of the digital pads in ostrich is thicker than fowl and the epidermal surface is covered with tightly packed papillae. We also noticed that these papillae are longer but slightly thinner as compared to those on emu foot (Milan, 2006). This variation may be due to the nature of ground surface and substrate of ostrich and emu. We suggest that the plantar surfaces of the footpads with a leathery appearance and durable sole covered by dense papillae, is more suitable for locomotion on various substrates. In parallel, Fränzi Korner-Nievergelt (2004) has found strong relationships between plantar skin morphology and microhabitat and non-volant locomotor behaviour.

The skin of the digital pad of ostrich consisted of an inner vascularized dermis and an outer non-vascular epidermis, the latter is composed of inner stratum germinativum and outer stratum corneum. The inner stratum germinativum consisted of mitotically, active basal layer, intermediate layer and thin transitional layer, similar results were found in skin of the foot and pads of passerines, parrots and owls (Lennerstedt, 1975). Examination of the histological section revealed that the stratum corneum of footpad of ostrich is composed of several layers of flattened horney cells with an outer conrnified layer assumed to be keratin acting as a mechanical barrier against abrasions. Our assumption is based on the finding that the heavily conrnified epidermis covering beaks, claws, spurs and the legs scales and feet contains keratin (Stettenheim 2000). In agreement with the findings of Spearman (1971), we found sharp demarcation between the transition- 
al cells and horny layers. The study found also that the basal layer consists of tall columnar epithelial cells with oval nuclei showed several mitotic figures indicating a high degree of proliferation. Similarly, epidermis of the hen foot pad showed high mitotic activity of these cells (Shtekher, 1966).

The histological study revealed the presence of multiple lipid droplets in the cytoplasm of the stratum germinativum cells (in all cell layers) and multigranular bodies (in transitional cells only). These droplets increased in size and connected with each other occupying very large spaces. In addition, some horney cells of the stratum corneum contained lipid droplets surrounded by a fibrous amorphous mass. Prior studies on the skin of mammals and birds have investigated that the lipid droplets and multigranular bodies in the epidermis can serve as permeability barrier (Landmann 1980; Menon et al., 1986, 1991, 1996, 2000; Wertz, 2000 and Lilly white 2006). Avian skin possessed highly lipogenic epidermis which has multigranular bodies (analogous to the lamellas bodies of mammals) the secretion of which resulted in formation of occlusive lipid bilayer that acts as a permeability barrier (Menon et al., 1986 and 1991). However in contrast to mammals, the avian multigranular bodies formed reserve barrier mechanism. Contents of the multigranular bodies were secreted into the extracellular domains of the stratum corneum as cells progress toward the stratum corneum (Wertz, 2000 and Lilly white 2006). A previous study has detected Keratohyaline masses in chick epidermis (Odland et al., 1964). In agreement with the previous authors, we also found some keratohyaline masses dispersed in the cytoplasm of the transitional cells of the epidermal footpad of ostrich.

Using electron microscope, the collagen fibers in the mid and deep dermis of the ostrich footpad were found to run parallel and connect to each other by very thin (assumed to be elastic) fibrils which are branched, crossed with each other in an oblique direction. Similar thin fibrils were detected throughout the whole dermis forming wide, meshed sponge of elastic fibers that creates constant extension of the skin of pigs (Meyer et al., 1981). When the dermis stretched in any axis, collagen fibrils became straightened and aligned in the direction of the extension resulted in greater dermal stiffness (Gibson et al., 1965; Ridge and Wright 1966). The greater extension of the dermis was due to rearrangement of fibers as they straightened and moved through gel 
like mucopolysaccharide ground substance surrounding them (Szirmai, 1968). Taken together, we suggested that such arrangement of these collagen fibers and thin fibrils is likely to be responsible for absorption of concussion and hence acceleration of the ostrich movement.

In ostrich foot, two digital cushions on the $3^{\text {rd }}$ digit and one cushion on the $4^{\text {th }}$ digit were observed. These cushions showed some structural and functional similarities to digital cushions of horse and bulb of heel of goat (Shanawany and Dingle, 1999 and Egerbacher et al., 2005), where they consisted of numerous adipocytes, few collagen fibers and they absorbed shock through deformation of their fat cells against strength of stretched reticulin fibers. However, digital cushion of horse contains few adipocytes, numerous collagen fibers and myxoid tissues as well as fibrocartilage (Egerbacher et al., 2005). Moreover, the digital cushion of ostrich and other ratites was contiguous along the planter aspect of weight bearing digit (Speer, 2003).

We have concluded that the skin of ostrich feet has evolved to cope with the mechanical demands of their terrestrial locomotion by forming unique modified structures including footpads and digital cushion which are adapted for long distance movement and protection of the underlying soft tissues.

\section{References}

Alexander, R. McN., G. M. O.

Maloiy, R. Njau and A. S. Jayes, (1979): Mechanics of running in the ostrich (Struthio camelus). J. Zool., Lond. 187, 169-178

Bennett, C.,(1997): Foot pad health and small laying hen flocks livestock knowledge. Winnipeg. Manaitoba. http: www. Gov.mb Co. agriculture.

Cooper, R, M. Mahrose, M. Elshafei, and I Mara, (2008): Ostrich farming. Journal of tropical animal health and production. Vol. (40) No. (5) pp. 349 -355 .

Deeming, D.C., (1999): The Ostrich Biology, Production and Health. CABI Publishing is a division of $C A B$ International

Egerbacher, M., M. Helmreich, A. Probst, H. König, and $P$. Böck, (2005): Digital cushions in horses comprise coarse C.T. myxoid tissue and cartilage but only little unilocular fat. Anat. Histol. Embryol. 34: 112 - 116.

Gibson,T., R.M. kendi and E. Craik, 
(1965):The mobile architecture of dermal collagen. $\mathrm{Br} \mathrm{J}$ Surg. 52:764-770.

Fränzi Korner-Nievergelt, (2004):

Correlation of foot sole morphology with locomotion behaviour and substrate use in four passerine genera $\mathrm{pp}$. 175 ;196. In Morphometrics applications in biology and paleontology. Editor Dr. Ashraf .M.T.Elewa.

Hallam, M. G., (1992):The Topaz in troduction to practical ostrich farming. Harare, Zimbabwe.

Harris H.F., (1900): The haematoxylins: In: Theory and Practice of Histological Techniques 2nd Ed. Bancroft J.D. and Stevens A. (eds.) Colchester and London.

Hayat, M., (1986): Basic techniques for transmission Electron Microscope, second ed. Academic press, Baltimore.

Keast, A., (1996): Wing shape in in sectivorous passerines inhabiting New Guinea and Australian rain forests and eucalyptic forest/eucalyptic woodlands. Auk 113: 94-

König, HE; Macher, R; PolstererHeindl, E; Sora, CM; Hinterhofer, C; Helmreich, M; Böck, P (2003): Stoßbrechende Einrichtungen am Zehenendorgan des Pferdes. Veterinary Medicine Austria /
Wiener Tierärztliche Monatsschrift (90) 267-273.

Landmann, L.,(1980): Lamellar gran ules in mammalian, avian and reptilian epidermis. J. Ultrastruct. Res. 72: pp. 245 $-263$.

Lennerstedt, I., (1975): A functional study of papillae and pads in the foot of passerines, parrots, and owls" Zoologica Scripta Vol. 4. 111-123.

Lilly White, H.B., (2006): Water relations of tetrapod integument. J. Exp. Biol. 209: pp. 202226.

Manlius, N., (2002): The ostrich in Egypt past and present. Journal of Biogeography Vol. (28) pp. 945-953.

McDowell A and F Trump, (1976):

Histologic fixatives suitable for diagnostic light and electron microscopy Arch Pathol Lab Med, 100: 405-415

Masson, P., (1929) : Trichrome staining and their preliminary technique. J. tech. Meth. and Bull. int. Ass. Med. Mus., 12, 75

Menon, G.K.; B. Brown and P. Elias, (1986): Avian epidermal differentiation role of lipids in permeability Barrier formation: tissue and cell. V. 18 No. 1. Pp. $71-82$.

Menon, G.K., S.Y.E. Hou and P.M. 
Elias, (1991): Avian permeability barriers function reflects mode of sequestration and organization of stratum corneum lipid: Revaluation utilizing Ruthenium tetroxide staining and lipase cytochemistry, Tiss cell. PP. $445-$ 456.

Menon, G.K., P.F. Maderson, R.C. Drewes, L.F. Baptista, L.F. Price and P.M. Elias, (1996): Ultrastructure organization of avian stratum corneum lipids as the basis for facultative cutaneous wateroofing. J. Morphol. 227 pp., 1-13.

Menon, G.K and J. Menon, (2000):

Avian epidermal lipid: functional considerations and relationship to feathering. Am. Zool.40 pp. 540-552.

Meyer,W., k. Neurand, and B. Rad ke, (1981): Elastic fiber arrangement in the skin of the pig. Arch. Dermatol. Res., 270:391-401.

Meyer, A., P. Cloete., R. Brown and S.J. van Schalkwyk, (2002): Declawing ostrich "Struthio camelus domesticus" chicks to minimize skin damage during rearing, south African $\mathrm{J}$. of animal science V. (32) 3. pp. 192-200.

Milản , J., (2006): Variations in the morphology of emu (Dromaius novahollandiae) tracks reflecting differences in walking pattern and substrate consistency: ichnotaxonomic implication .Palaeontology, Vol. 49, Part 2, pp. 405-420

Odland, G.F., W. Montagna and W. Lobitz, (1964): (eds), the Epidermis, pp. 237-249. Academic press, New York.

Ridge,M. and V. Wright, (1966): The directional effects of the skin. J. Invest Dermatol. 46:341346.

Raikow,R.J.,(1985): Locomotor systems. In: King AS, McLelland $\mathrm{J}$ (eds) Form and Function in Birds. Academic Press, London, pp 57-147

Shanawany,M.and J.Dingle, (1999): Ostrich production system food and Agriculture org.

Shtekher, S., (1966): The rate of physiological regeneration of avian epidermis. Translated from by ulleten, Eksperimental noi Biologii Meditsing. Vol. 61 , No. 3 pp. $323-315$.

Spearman, R., (1971): The integument, a text book of skin biology. Vol. (3). Cambridge university press.

Speer, B., (2003): Ratite Neuromuscular disease. WW. net pets, org/birds/health spa/Vet/ratite. html.

Stettenheim, P., (2000): The integumentary morphology of modern birds an over view 
.Intergative and comparative

biology.vol.40 (4) :461-477.

Szirmai, J., (1968): The organization of the dermis. Advances in biology of skin dermis, vol. Edited by $\mathrm{W}$ Montagna, JP Bentely, RI Dobson Appleton-Century-Croft pp1-17

Wertz, P.W.,(2000):Lipids and barrier function of the skin. Acta. Derm. Venersel., supp. 208 pp. 7-11.

Corresponding author. Samir A.A. El-Gendy elgendyanatomist@yahoo.com

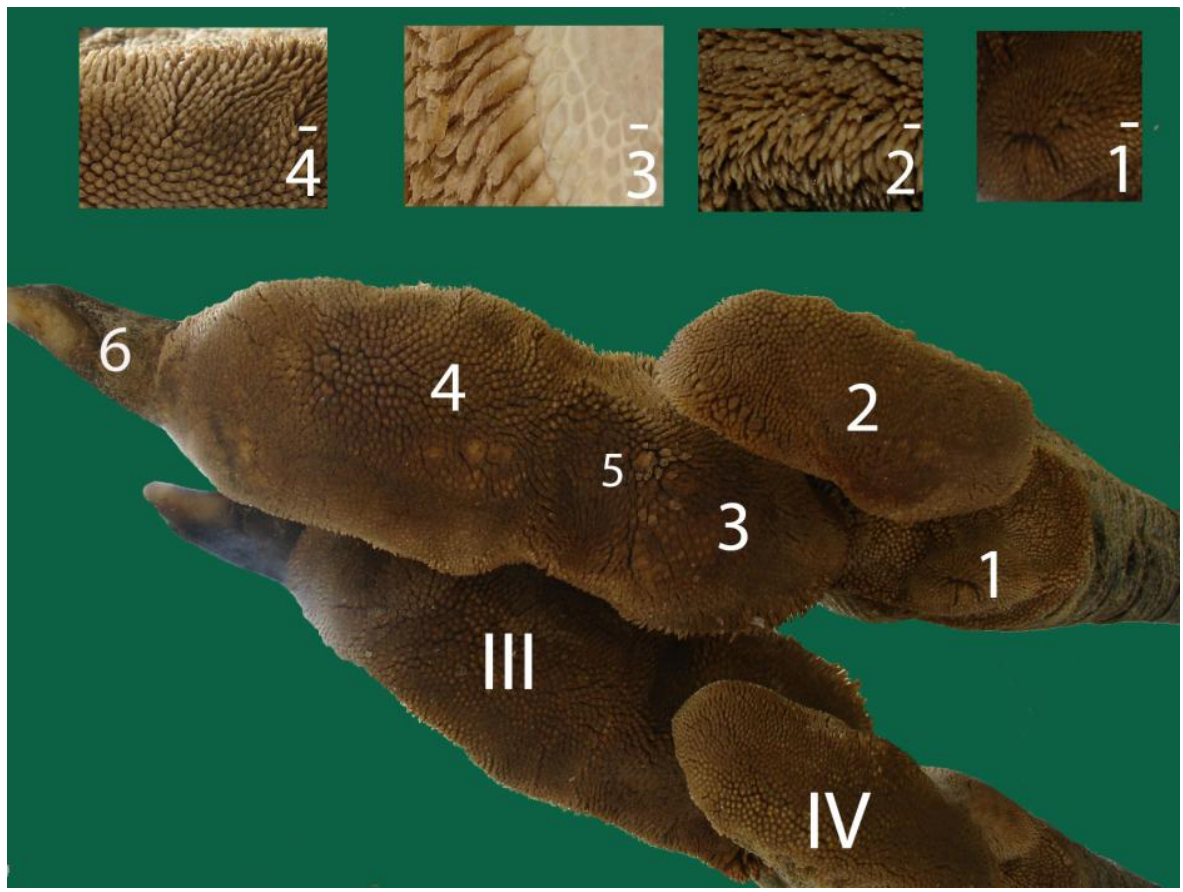

Fig (1): A light photograph of planter view of ostrich feet.

III third digit; IV fourth digit; 1 metatarsal phalangeal pad; $1^{-}$enlarged photo of the metatarsal phalangeal pad showing dome and horny shaped papillae; 2 foot pad of $4^{\text {th }}$ digit; 2 enlarged part of the foot pad of $4^{\text {th }}$ digit showing the shape and direction of the papillae; 3 caudal foot pad of $3^{\text {rd }}$ digit; $3^{-}$enlarged part of the dissected caudal foot pad of $3^{\text {rd }}$ digit showing the rectangular origin of its papillae; 4 cranial foot pad of $3^{\text {rd }}$ digit, $4^{-}$ enlarged part of the cranial foot pad of $3^{\text {rd }}$ digit showing pointed and blunt ends papillae running in different directions; 5 interpad groove; 6 foot nail. 


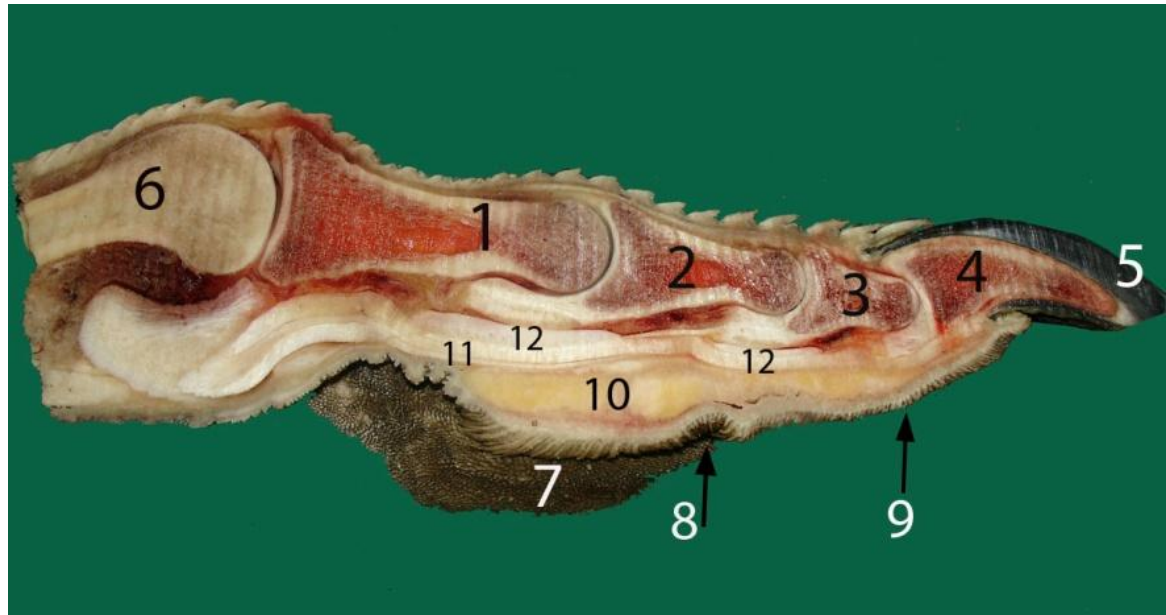

Fig (2): Photograph of a sagittal section through the third digit of ostrich foot.

1 first phalanx; 2 second phalanx; 3 third phalanx; 4 fourth phalanx; 5 toe nail; 6 tarsometatarsus bone; 7 caudal foot pad of the $3^{\text {rd }}$ digit; 8 interpad groove; 9 cranial foot pad of the $3^{\text {rd }}$ digit; 10 abaxial cushion; 11 tendon of the $\mathrm{M}$. flexor perforans et perforatus digiti III; 12 tendon of M. flexor digitorum longus

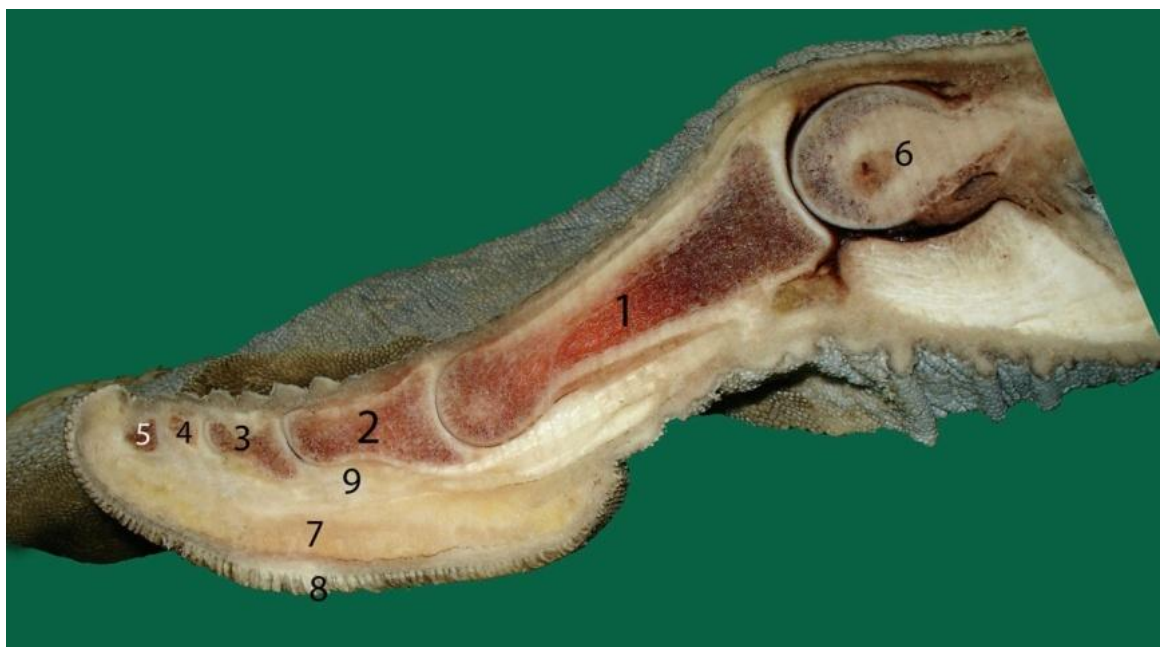

Fig (3): Photograph of a sagittal section through the fourth digit of ostrich foot.

1 First phalanx; 2 Second phalanx; 3 Third phalanx; 4 Fourth phalanx; 5 Fifth phalanx; 6 tarso-metatarsus bone; 7 Digital cushion; 8 Foot pad papillae of the fourth digit; 9 Tendon of the M. flexor digitorum longus of fourth toe. 


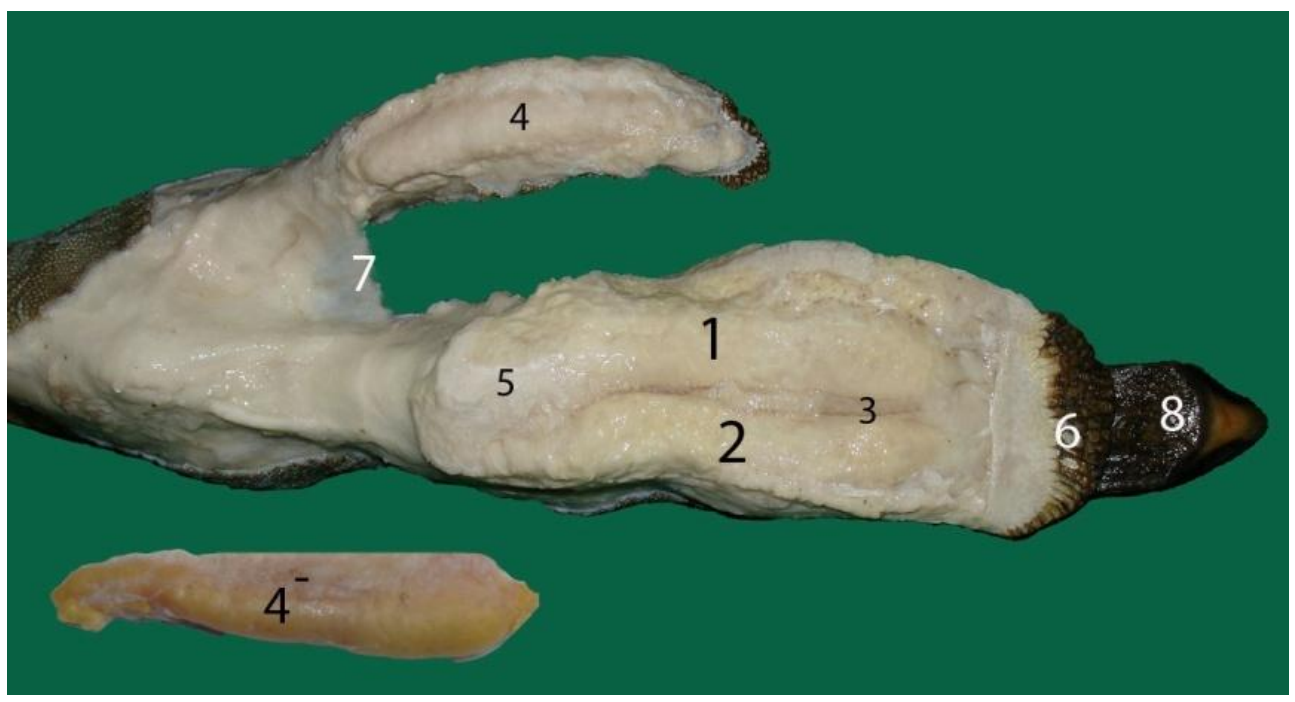

\section{Fig (4): Photograph of planter view of ostrich foot. The skin is removed.}

1 Abaxial cushion of digit III; 2 Axial cushion of digit III; 3 Groove filled with fibrous tissue; 4 Digital cushion of digit IV; 4 Fresh digital cushion of Digit IV, fatty yellow color; 5 fibrous tissue enclosed the cushions; 6 Papillae of cranial foot pad; 7 Partial interdigital septum; 8 Claw.
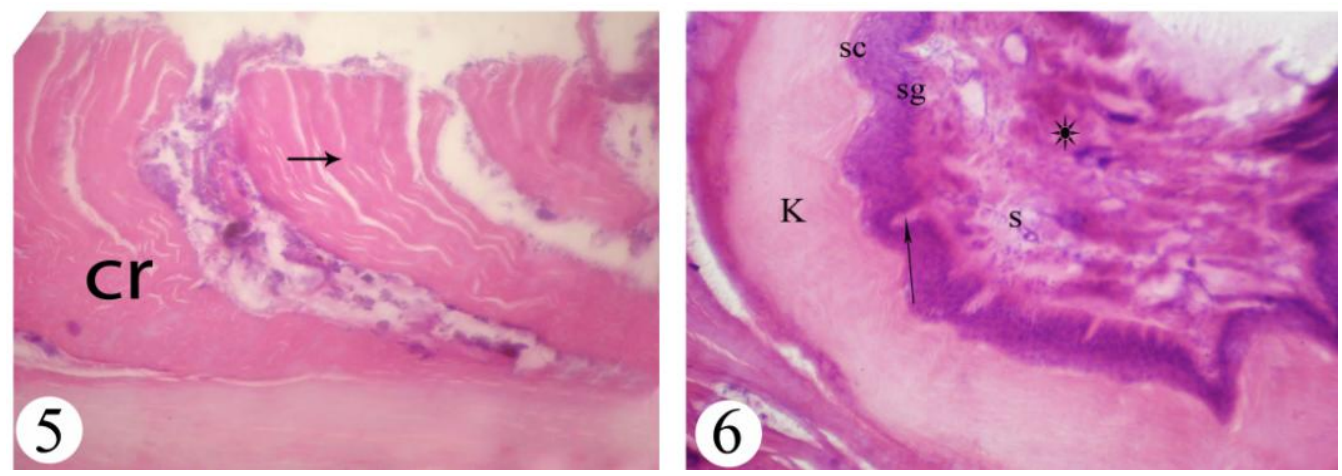

Fig (5): Photomicrograph of the footpad of ostrich showing rods (papillae) (arrow) of cornified structure (cr). (X10, stain H\&E)

Fig (6): Photomicrograph of the skin of the footpad showing inner stratum germinativum (sg) and outer stratum corneum (sc) of the epidermis and superficial layer of dermis (s), deep layer of dermis ( $\left.{ }^{*}\right)$.

Note dermal papillae (arrow). Keratin (k). (X25, stain H\&E) 

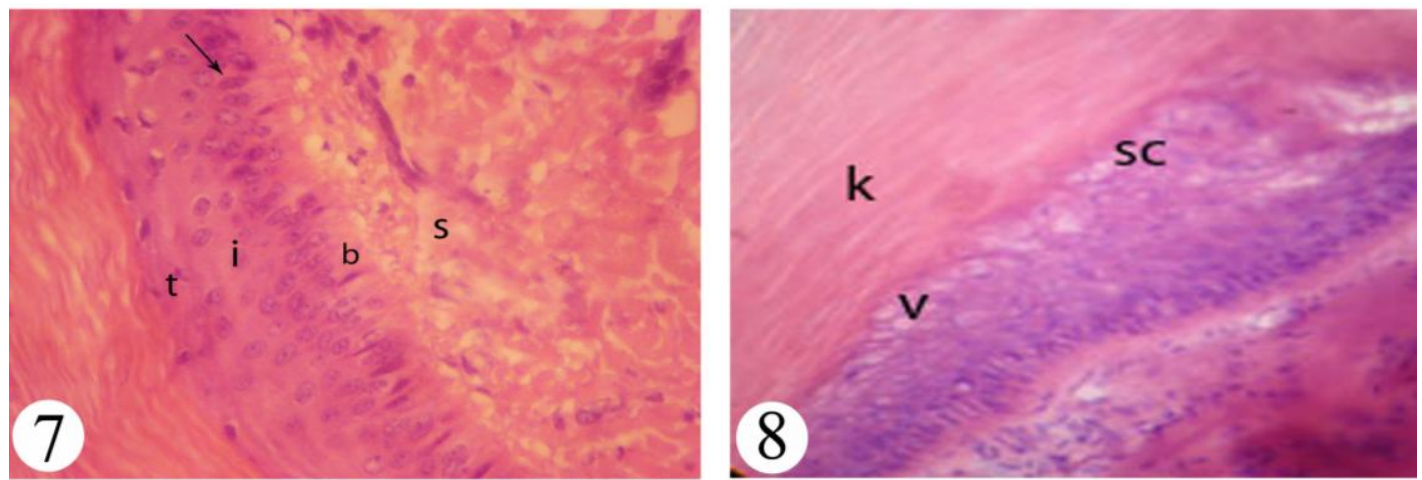

Fig (7): Light photograph of skin of footpad showing mitotic figures (arrow) at the basal layer (b) of stratum germinativum, inter mediate layer (i) and transitional layer(t) of stratum germinativum and superficial dermis (s).( $X 40$, stain $\mathrm{H} \& E)$

Fig (8): Photomicrograph of the epidermis of footpad showing vacuoles (v) of stratum corneum (sc).Keratin (k) (X 40, .stain H\&E)
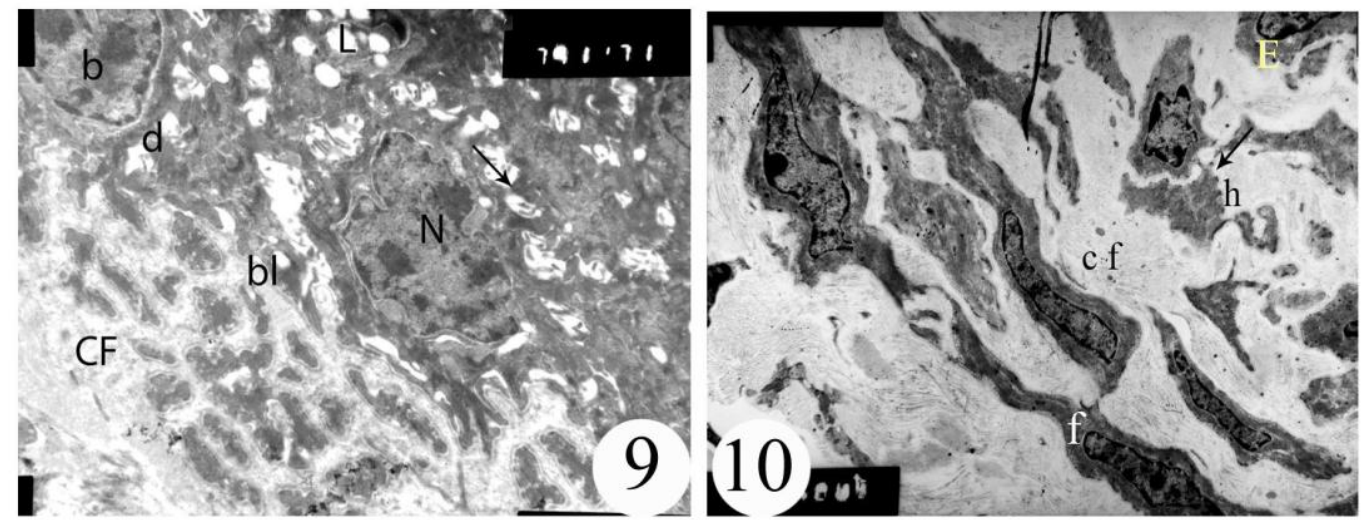

Fig (9): Transmission electron micrograph of basal cells (b) of stratum germinativum showing some lipid droplets (L), interdigitations of adjacent plasma membranes (arrow), desmosomes $(\mathrm{d})$, darkly stained nuclei $(\mathrm{N})$, basal lamina (bl) and collagen fibers (CF). $(\mathrm{X} 7,500)$

Fig (10): Electron micrograph of superficial layer of dermis displaying collagen fibrils (cf), basal epithelial cells (E) surrounded by parts of basal lamina (arrow) showing hemidesmosomes (h). Fibroblast (F). (X5, 000) 

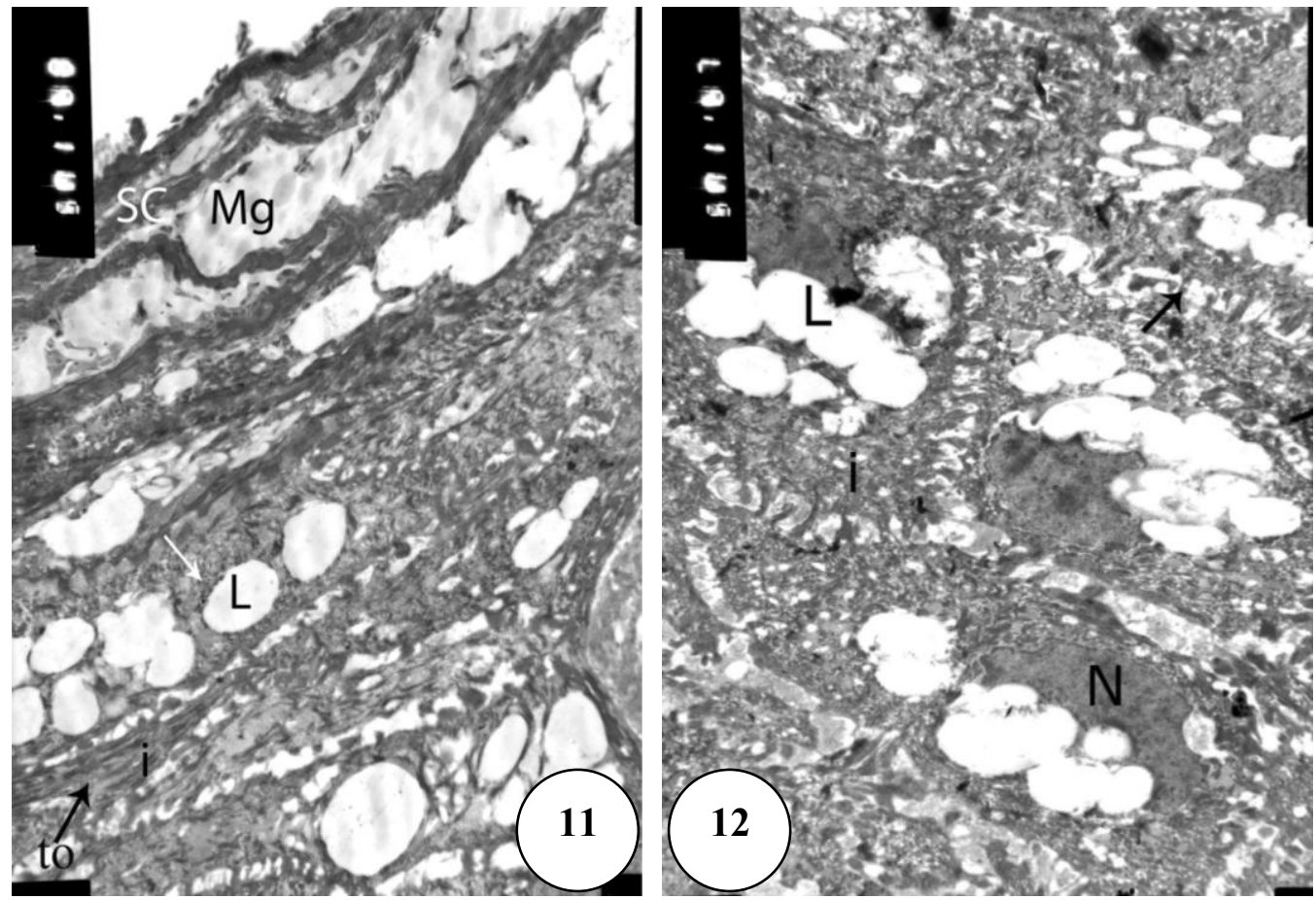

Fig (11): Electron micrograph of transitional cells $(\mathrm{t})$ denoting multiple lipid droplets (L) separating intermediate cells (i), tonofibrils (to) and the stratum corneum (SC). Note: multigranular bodies (Mg) and keratohyaline (arrow), X7, 500 .

Fig (12):Transmission electron micrograph of the intermediate cells (i) of stratum germinativum showing multiple lipid droplet $(\mathrm{L})$, Interdigitations of adjacent plasma membranes (arrow) and Nucleus (N).Micro. Mag. X5, 000 

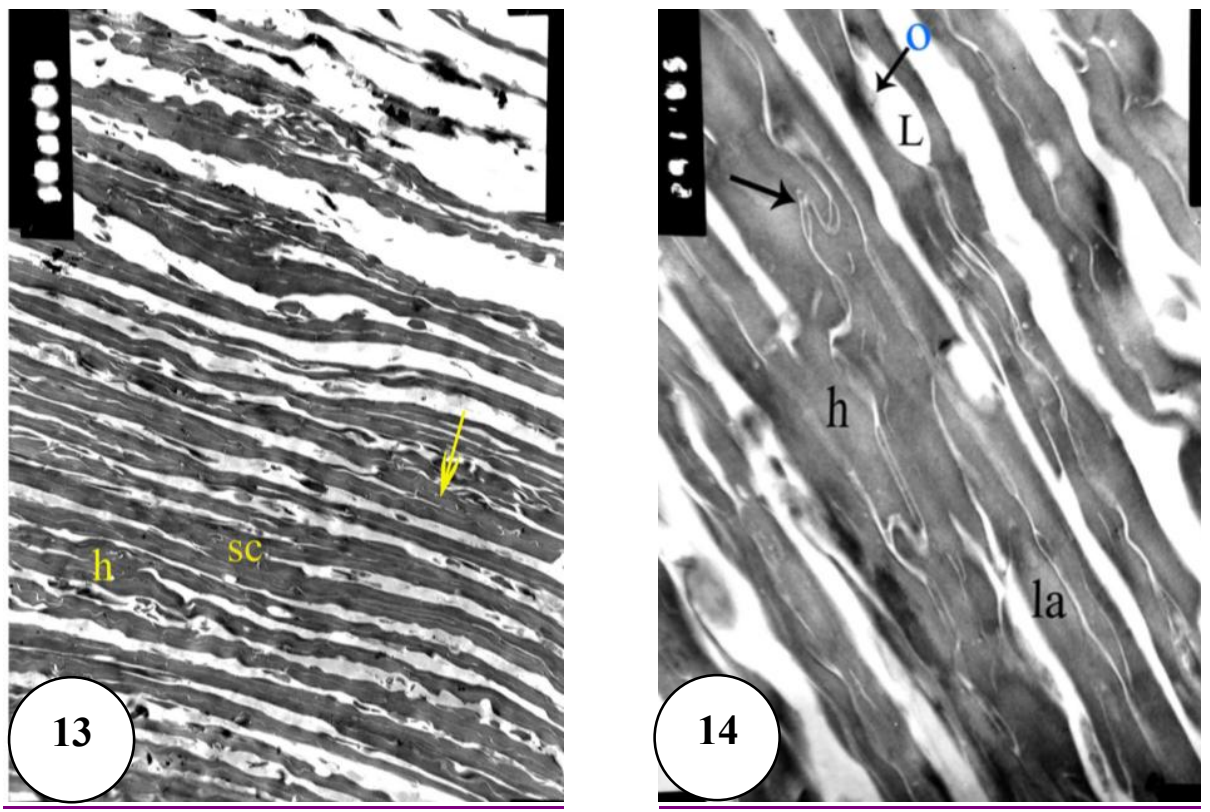

Fig (13): Transmission electron micrograph of the stratum corneum (SC) showing honey flattened cells $(\mathrm{h})$ with interdigitations (arrow). (X5,000)

Fig (14): A higher magnification of Fig.(13) denoting horney cells (h) with interdigitations (arrow), lipid droplets (L) with amorphous material (o) and lamellae of horney cells (la).. $(\mathrm{X} 25,000)$

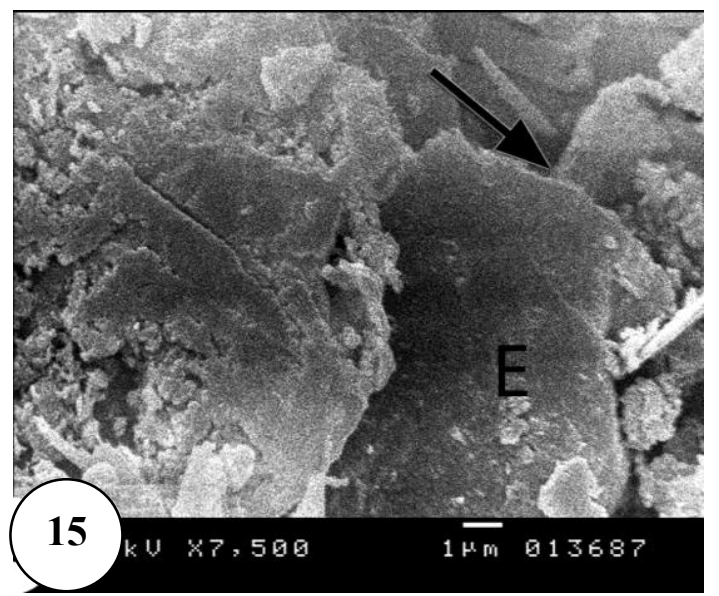

Fig. (15): Scanning electron micrograph of the superficial layer of the footpad papillae (epidermis of the foot pad) showing a partial overlapped (arrow) hexagonal squamous cells $(E) . \quad(X 7,500)$ 

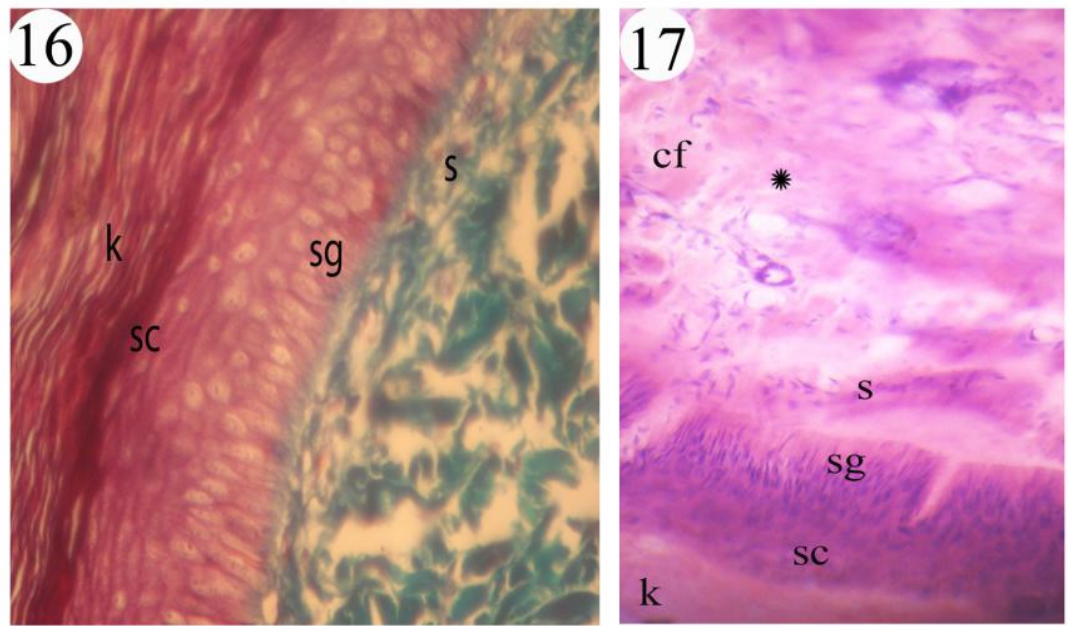

Fig (16): Photomicrograph showing stratum corneum (sc), stratum germinativum (sg) and superficial dermal layer (s). Keratin (k) ( X 40, stain trichrome)

Fig (17): Photomicrograph of the dermis of the footpad showing loosely arranged collagen fibers (cf) of superficial dermal layer (s). Stratum germinativum (sg), Deep dermal layer $\left({ }^{*}\right)$, Stratum corneum (sc) and Keratin (k) (X 25, stain H\&E)
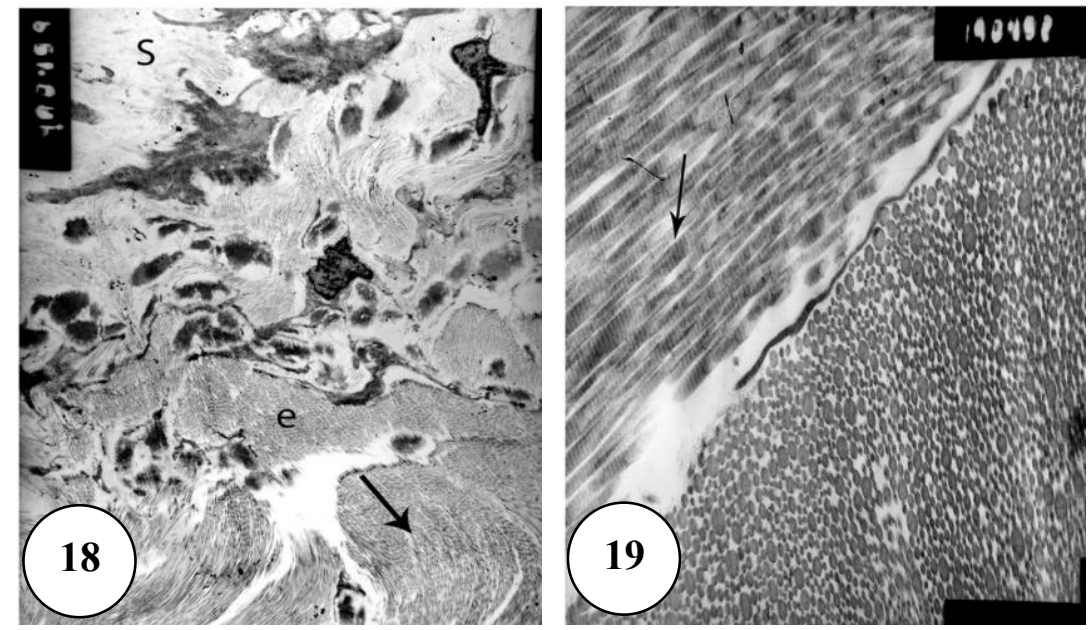

Fig (18): Electron micrograph of the superficial layer (s) and deep layer (e) of dermis denoting bundles of discretely organized collagen fibrils (arrow). (X4, 000)

Fig (19): Electron micrograph of longitudinal and cross section of collagen fibrils showing periodic banding of collagen fibrils (arrow). (X5, 000) 

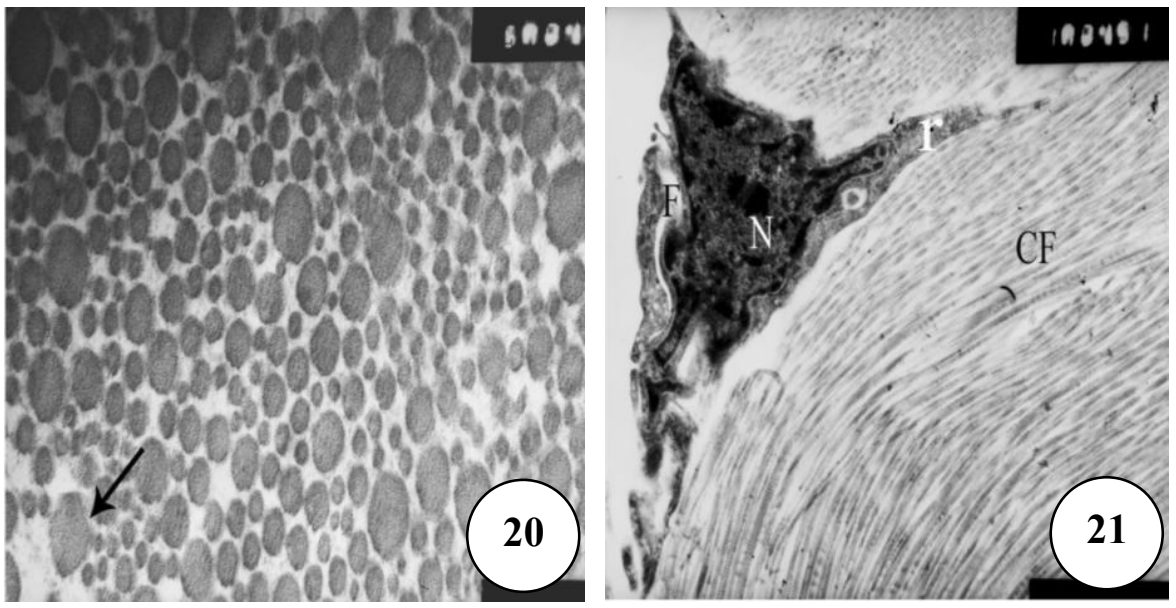

Fig (20): A higher magnification of previous photo denoting broad range in fibril diameter and hexagonal appearance of collagen fibrils (arrow). (X50, 000)

Fig (21): Transmission electron micrograph of the deep layer of dermis showing satellite shape fibroblast $(f)$ with darkly stained nucleus $(N)$, few ribosomes ( $r$ ). Collagen fibrils (cf). (X10, 000)

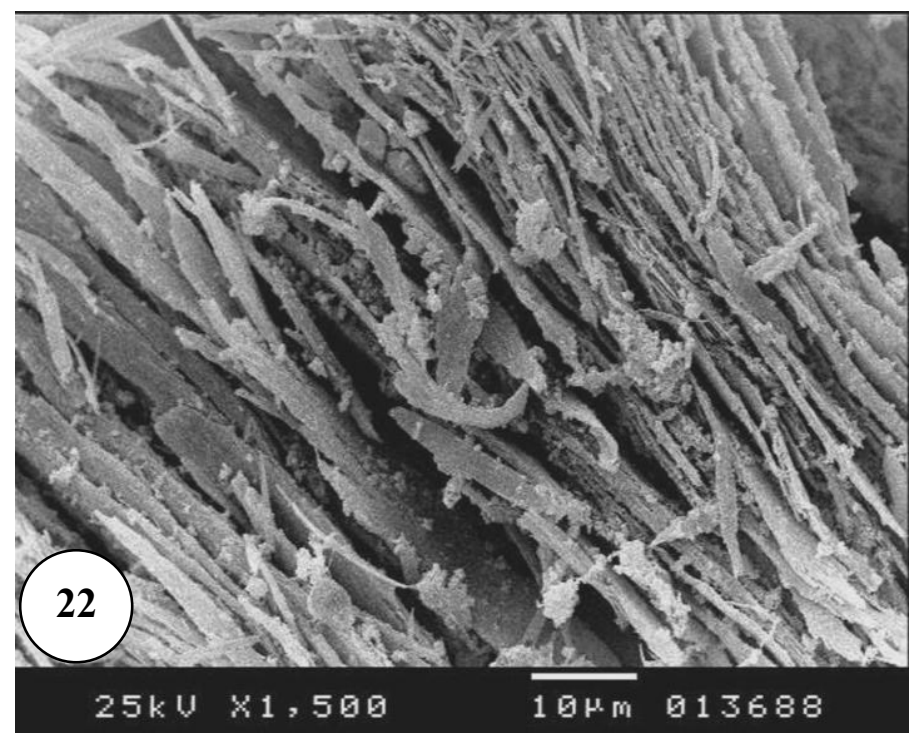

Fig (22): Scanning electron micrograph of the upper layers of dermis showing the collagen fibers parallel each other running diagonally to the skin surface $(X 1,500)$ 

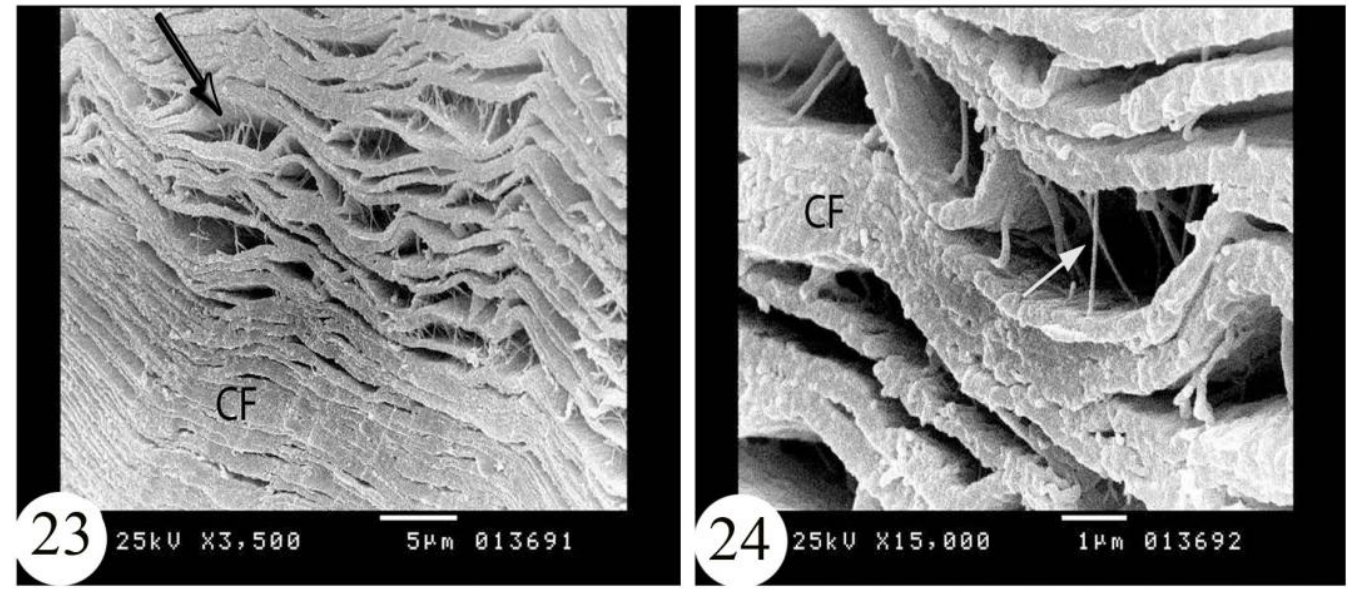

Fig.(23): Scanning electron micrograph of sagittal section of papillae showing the collagen fibers (CF) in the mid and deep dermis, arranged parallel to each other and connected by thin branched fibrils (arrow) $(\mathrm{X} 3,500)$

Fig (24): Higher magnification of previous photo depicting the collagen fibers (CF) and the thin branched elastic fibrils (arrow) connect them. (X15, 000)
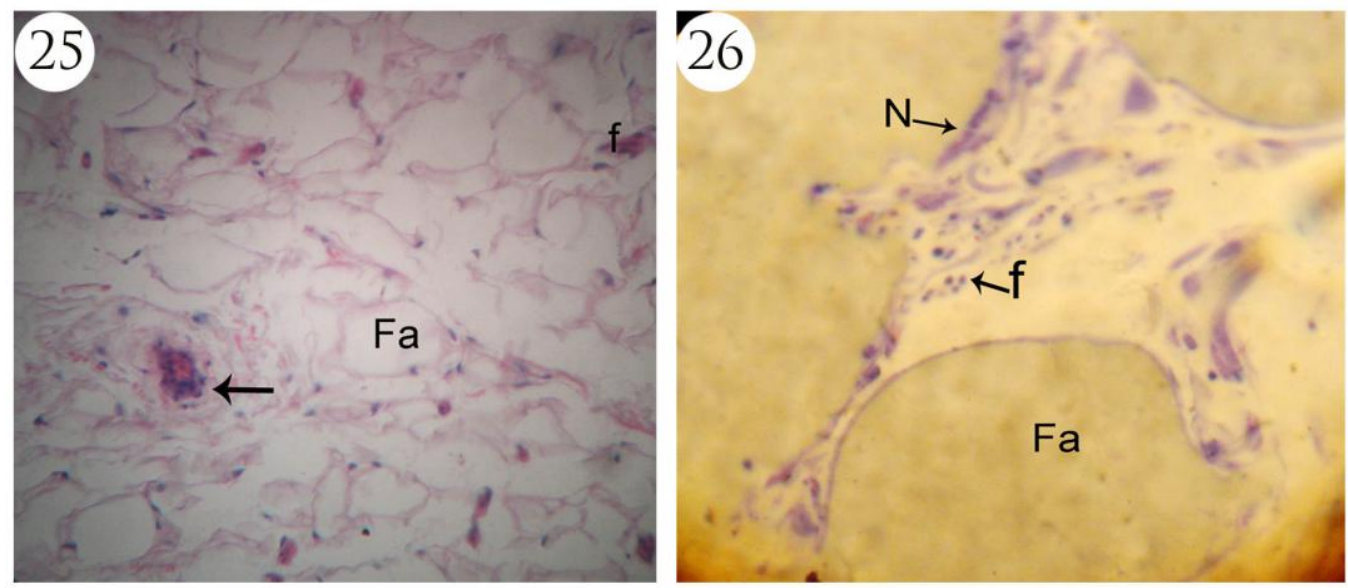

Fig (25): Photomicrograph of a digital cushion showing, fat cells (Fa), blood vessels (arrow), fibroblast (f). (X 40, stain H\&E)

Fig (26): Photomicrograph of a digital cushion showing, fat cells $(\mathrm{Fa})$ with peripherally located nucleus $(\mathrm{N})$, fibroblast (f). (X 100, toluidine blue stain) 


\section{Animal species in this issue}

\section{The domestic dog (Canis Iupus familiaris)}

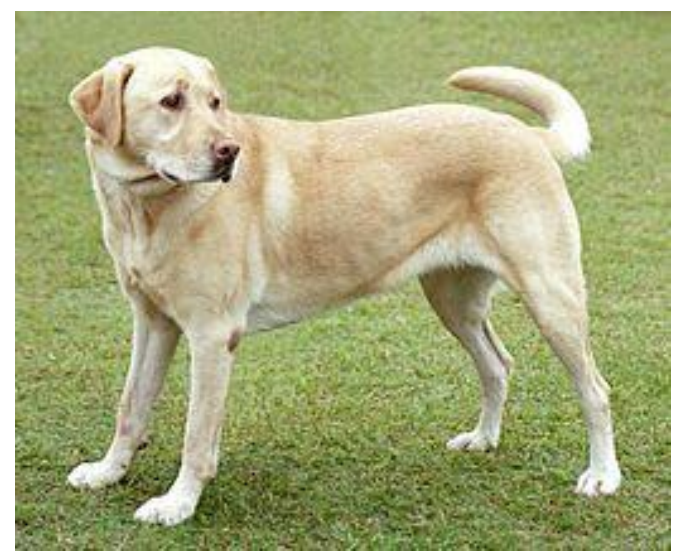

Kingdom: Animalia\& Phylum: Chordata\& Class: Mammalia \& Order: Carnovora\& Family: Canidae\& Genus: Canis\& Species: C.lupus\& Subspecies: C. I. familiaris and C. I. dingo

The term dog is used for both feral and pet varieties. The dog may have been the first animal to be domesticated, and has been the most widely kept working, hunting, and companion animal in human history. The word "dog" may also mean the male of a canine species, as opposed to the word "bitch" for the female of the species.

Dogs were domesticated from gray wolves about 15,000 years ago. Their value to early human settlements led to them quickly becoming ubiquitous across world cultures. Dogs perform many roles for people, such as hunting, herding, pulling loads, protection, assisting police and military, companionship, and, more recently, aiding handicapped individuals. This impact on human society has given them the nickname "Man's Best Friend" in the Western world. In 2001, there were estimated to be 400 million dogs in the world.

Compared to equally sized wolves, dogs tend to have $20 \%$ smaller skulls, $30 \%$ smaller brains, as well as proportionately smaller teeth than other canidspecies, Dogs require fewer calories to function than wolves. It is thought by certain experts that the dog's limp ears are a result of atrophy of the jaw muscles. The skin of domestic dogs tends to be thicker than that of wolves, with some Inuit tribes favoring the former for use as clothing due to its greater resistance to wear and tear in harsh weather. 